\title{
Dossier: "Los estudios judíos desde Latinoamérica: temas, perspectivas y diálogos con otras agendas académicas"
}

Coordinan

Dra. Daniela Gleizer (UNAM)

Dr. Emmanuel Kahan (IdIHCS-CONICET/UNLP - NEJ-IDES)

Los estudios judíos latinoamericanos parecen estar atravesando uno de sus mejores momentos. Si bien el interés por esta área de estudios dista de ser nueva, la multiplicación de la producción académica en los últimos años revela no solo un creciente interés de los investigadores sino también una mayor apertura y diversificación de los temas tratados y las perspectivas adoptadas. La producción académica sobre el judaísmo latinoamericano ha sido resultado de la acción de tres polos, Estados Unidos, Israel y, de manera desigual, los propios países latinoamericanos.

Su origen y desarrollo estuvo estrechamente ligado a la acción de dos asociaciones académicas. La primera, AMILAT, acrónimo hebreo para Asociación Israelí de Investigadores del Judaísmo Latinoamericano, fue creada en 1975 por investigadores egresados o pertenecientes a la División de América Latina, España y Portugal del Instituto Harman de Judaísmo Contemporáneo de la Universidad Hebrea de Jerusalén, dirigida desde su fundación en 1967 por el Prof. Haim Avni. La segunda organización es LAJSA, fundada en 1982 en Estados Unidos por profesores de universidades norteamericanas, algunos de ellos latinoamericanos. El impulso y dirección inicial de LAJSA fue la Prof. Judith Laikin Elkin.

Uno de los signos más auspiciosos del desarrollo de los estudios judíos latinoamericanos ha sido la aparición en los últimos años de un interesante debate epistemológico, iniciado desde Brasil por el sociólogo Bernardo Sorj (2007) y ampliado -desde distintas posiciones- por los historiadores Raanan Rein de la Universidad de Tel Aviv y Jeffrey Lesser de la Universidad de Emory (2008), y Judit Bokser Liwerant, de 
la UNAM (2011). Estos investigadores, junto a otros que han participado de este debate, han promovido la renovación de los temas y perspectivas de análisis apuntando a cuestiones poco abordadas tales como tensiones y diferenciales de poder dentro de las comunidades, el papel de las mujeres, las comunidades e individuos de origen sefaradí, los judíos no afiliados, los judíos latinoamericanos que viven en otros países, entre otros temas. También han sugerido la necesidad de adoptar perspectivas comparativas que permitan contrastar la experiencia de los judíos con la de otros grupos étnicos, así como la experiencia de los judíos latinoamericanos con la de los judíos de otras partes del mundo.

Estas nuevas aproximaciones a un objeto de estudio cuya característica es su diversidad -incluso al interior de los Estados nacionales que componen el continente- se inscribían en diversas agendas de debate académico. Uno de los rasgos que caracterizaron el intercambio de perspectivas era la propia trayectoria e inserción institucional de los investigadores intervinientes en la polémica: quienes llevaron la voz cantante se encontraban inscriptos, mayoritariamente, en centros de investigación radicados en Universidades situadas por fuera del territorio que se puede denominar como "latinoamericano".

Sin embargo, la producción académica presentada en los foros anteriormente citados LAJSA y AMILAT- evidencia una relevante y seria producción de investigaciones acerca de las diversas experiencias en torno a lo "judío" cuyos autores provienen y/o están insertos en diversas agencias estatales y/o Universidades de los países latinoamericanos. Estos trabajos se inscriben en agendas de producción y debate vinculadas a sus propios entornos: la "cuestión judía" en los contextos de violencia política, el lugar de lo "judío" en los procesos de elaboración y transmisión de la memoria, las diversas formas o mecanismos bajo los cuales los judíos institucionalizados y no afiliados- participan en la escena política nacional, etcétera.

A diferencia de las producciones académicas realizadas en centros de pesquisa situados en Estados Unidos, Canadá e Israel - por mencionar tan sólo algunos- los estudios 
judíos realizados desde Latinoamérica se encuentran en proceso de legitimación en los campos académicos locales. Es por este motivo que el presente Dossier se propone problematizar las agendas y perspectivas con las cuales se aborda la experiencia judía en América Latina en contextos nacionales de producción académica.

No obstante, esta formulación requiere una reserva de orden epistemológico: "lo latinoamericano" como objeto comprende un extenso número de países, así como temporalidades muy distintas. Si bien existen bases históricas, culturales e idiomáticas que acercan a la mayor parte de los países de la región, las diferencias entre ellos son sustanciales. Solo por contraste con otras regiones, y a partir de la enunciación analítica o política, es posible trazar una unidad. Lo mismo sucede con la historia judía en la región. Si bien desde un punto de vista muy general podemos identificar elementos comunes que definieron un contexto singular para el desarrollo de la vida judía en América Latina, tales como la religión (catolicismo) y las lenguas dominantes (castellano y portugués), son muchas las particularidades que diferencian las experiencias de vida judía entre sí. Esto se observa, primero, en las dimensiones y grados de desarrollo institucional de las distintas poblaciones judías, y en las implicancias sociales, culturales y políticas de estas diferencias.

Estas experiencias convergentes y divergentes, a la vez, se observan a partir de los modos en que la especificidad de cada contexto político, social y cultural nacional condicionó los modos de integración de los judíos, así como su desarrollo y configuración comunitaria. Son estos mismos derroteros, como evidencian los trabajos que componen este Dossier, los que permitirán comprender el grado de avance, reconocimiento e institucionalización de los estudios judíos en los países abordados: Argentina, Brasil, Cuba, Chile, México y Perú. ${ }^{1}$

1 Esta selección no aborda la totalidad de la producción académica producida en contextos nacionales latinoamericanos; sino que es producto de la voluntad de algunos investigadores de participar en el relevamiento solicitado para el presente Dossier. 
Este Dossier tiene como antecedente un panel titulado "Los estudios judíos desde América Latina", que tuvo lugar en el marco del XVII Congreso Internacional de LAJSA, en la ciudad de Miami, convocado por Emmanuel Kahan. El fructífero intercambio generado a partir de dicho encuentro, y el interés de muchos miembros de LAJSA por la propuesta de la mesa nos condujeron a considerar pertinente la agrupación y publicación de los trabajos presentados, en forma de artículos elaborados particularmente para este número de la Revista Cuadernos Judaicos.

Para poder organizar las presentaciones en torno al estado de situación del campo de investigación en estos países, cada trabajo abordó -tanto para el panel como para el dossier- una serie de preguntas ordenadoras: 1) ¿Cuáles son las diversas líneas de trabajo e investigación acerca de los judíos que se realizan en los países de los expositores? 2) ¿En qué medida esos temas dialogan, se inscriben y/o son subsidiarios de la agenda de debates académica local? 3) ¿Qué rasgos permiten observar el modo en que lo "judío" dialoga con otros colectivos sociales y nacionales? 4) ¿Cuáles son las vías de "institucionalización" que atraviesan los estudios judíos en cada uno de los países de los participantes del panel? Aun así, es necesario advertir al lector que se trata de textos muy distintos, y que, como coordinadores, respetamos los diversos enfoques metodológicos de los autores.

Esperamos que nuestra propuesta de pensar los estudios judíos sobre América Latina desde América Latina enriquezca el campo y abra nuevas preguntas y rutas de investigación. También esperamos que, en el futuro, se sumen más investigadores para arrojar luz sobre los estudios judíos en los países latinoamericanos que no aparecen en el presente dossier. 


\section{Bibliografía}

Bokser Liwerant, Judit et. al., 2011, "Cuarenta años de cambios: transiciones y paradigmas", en Avni, Haim et. al., Pertenencia y alteridad. Judios en/desde América Latina: cuarenta años de cambios, Madrid, Iberoamericana, pp. 13-83.

Lesser, Jeffrey and Raanan Rein, 2008, "New approachers to ethnicity and Diaspora in Twentieth-Century Latin America" in Lesser, J. y Rein, R. (eds.), Rethinking JewishLatin Americans, University of New Mexico Press, Pp 1-22.

Sorj, Bernardo, 2007, "The elusive field of Jewish Latin American Studies", Latin American and Caribbean Ethnic Studies, Volume 2, pp. 207-212. 